\title{
Sorghum: An Important Source of Bioactive Compounds
}

\author{
Cabrera-Ramírez AH ${ }^{1}$, Gaytán-Martínez $\mathbf{M}^{2 *}$ and Morales-Sánchez $\mathrm{E}^{1}$ \\ ${ }^{1}$ Instituto Politécnico Nacional, CICATA-IPN Unidad Querétaro, México \\ ${ }^{2}$ Research and Graduate Studies in Food Science, Universidad Autónoma de Querétaro, México
}

*Corresponding author: Dra. Marcela Gaytán-Martínez, Posgrado en Ciencia y Tecnología de los Alimentos, Research and Graduate Studies in Food Science, School of Chemistry, Universidad Autónoma de Querétaro, Centro Universitario, Santiago de Querétaro, C.P. 76010, Qro, Mexico.

To Cite This Article: Gaytán-Martínez M, Sorghum: An Important Source of Bioactive Compounds. 2020 - 8(2). AJBSR.MS.ID.001253.

DOI: $10.34297 /$ AJBSR.2020.08.001253.

Received: 眥 February 18, 2020; Published: 眥 March 17, 2020

\section{Mini Review}

Sorghum is the fifth most-produced cereal worldwide, where the USA, China, and Mexico were the largest producers in 2017 [1]. Sorghum has nutritional characteristics such as protein contents up to $12 \%$, lipids $4.7 \%$, ashes $2 \%$, and carbohydrates $80 \%$, depending on the variety $[2,3]$. Recently, it has been proven that sorghum could be considered as gluten-free food since regardless of the variety, it has a maximum of $5 \mathrm{ppm}$, which allows its consumption in celiac people [4-6]. Several studies have shown the sorghum as a valuable source of bioactive compounds, where its lipid profile, phenolic compounds, and fiber content (soluble, insoluble, resistant starch, and $\beta$-glucans) stand out. The sorghum lipid profile consists mainly of waxes and oils (2:1), whose oil fraction contains about $90 \%$ linoleic, stearic, and palmitic acid [7]. A 2005 study showed that the sorghum lipid extracts (SLE) in concentrations of 1 and $5 \%$ helped to reduce non-HDL cholesterol by 36 and 69\%, respectively, in Syrian male hamsters F1B [8].

Similarly [9] showed a reduction of $30.31 \%$ in non-HDL cholesterol in plasma, as well as a $46.13 \%$ in the liver esterified cholesterol, by providing $5 \%$ of SLE using male hamsters model (F1B) [9]. Lastly, in 2009 using a hypercholesterolemia hamster model, [10] observed the same behavior after mentioned, attributing this effect to an improvement in cholesterol metabolism as a result of alterations in the intestinal microbiota, suggesting a possible prebiotic effect in SLE [10]. Sorghum is plentiful in phenolic compounds such as simple phenolic acids (ferulic acid and p-coumaric acid), flavones, flavonoids, and 3-deoxyantocyanidins (3-DXAs), and polyphenolic compounds like condensed and hydrolyzed tannins $[11,12]$. These phenolics compounds found in sorghum are ef fective antioxidants, even higher than those found in blueberries, strawberries, and grapes, using the ORAC method [7].

AL Burdette [13] showed that apigenin, gallic, and ferulic acids from sorghum suppressed the production of cyclooxygenase-2 (COX-2), and tumor necrosis factor- $\alpha$ (TNF- $\alpha$ ), as well as the inhibition of nuclear factor- $\kappa \mathrm{B}$ (NF- $\kappa \mathrm{B})$ in macrophages activated by lipopolysaccharides [13]. On the other hand, 3-DXAs have been shown to inhibit the growth of cancer cells of leukemia (HL-60) and hepatoma cells (Hepg2) [14]. Besides, they have shown a chemoprotective effect of 3-DXAs by the induction of detoxifying and antioxidant enzymes through intracellular activation of NF-E2 [15]. Further, sorghum phenolic extracts (SPE) have been shown to reduce the expression of IL- $\beta$ and TNF- $\alpha$ proinflammatory cytokines by up to 30 and $80 \%$, respectively [16]. Likewise, SFE has reduced the reactive oxygen species (ROS) levels [17], COX-2, and iNOS [18], as well as a reduction of the nitric oxide production in macrophages with doses of 5.23 to $6.23 \mathrm{mg} / \mathrm{mL}$ [19]. Similarly, condensed tannins have reduced the activity of melanocytes and formation of melanomas in the colon after administration of doses from 200 to $1000 \mathrm{mg} / \mathrm{mL}$ [20]. Furthermore, phenolic compounds have shown a hypoglycemic effect by reducing the activity of $\alpha$-amylase [21].

In the same way, systemic effects on glucose metabolism, such as increased AMPK [22], as well as overexpression of PPAR- $\gamma$ [23], have been reported. The sorghum fiber fractions have been of interest, mainly the resistant starch (RS), which has been one of the most studied. It has been reported that sorghum can contain up to $65 \%$ of RS, depending on the variety, where brown sorghums had the highest content [24]. Most of the studies on sorghum's RS 
have been focused on their content and the effect of the processing [25,26]. However, [27] showed that consumption of isolated RS from sorghum modulated the colonic microbiota, increasing in the population of Lactobacillus and Bifidobacteria, while a decrease in E. Colli was observed. Additionally, this study showed a decrease in blood triacylglycerols after the sorghum RS intake, suggesting a potential use for the prevention and treatment of obesity [27].

S Wathsala [28] shown that RS from whole sorghum stimulates the production of short-chain fatty acids (SFACs) during the colonic fermentation, proposing that sorghum RS may act as a prebiotic. Additionally, higher production in propionate, butyrate, and total SFACs has been observed in sorghum RS compared to the control [28]. In summary, sorghum is a valuable source of multiple compounds with potential biological impacts, since their nutritional features to the presence of phytochemicals and compounds such as fiber, that showed beneficial effects on the health in several studies in animal models. Nevertheless, studies focused on the beneficial effect of RS in sorghum are still limited, which mainly are focused on isolated RS, so that studies are still required to evaluate the effect of whole sorghum products on resistant starch and its beneficial effects. Future research should develop to prove the beneficial effects of different sorghum components in human health.

\section{References}

1. (2019) Grain: World Markets and Trade. United States Dep. Agric. Foreign Agric. Serv USDA.

2. EE Llopart, SR Drago (2016) Physicochemical properties of sorghum and technological aptitude for popping. Nutritional changes after popping. LWT - Food Sci Technol 71: 316-322.

3. M Gaytán Martínez (2017) Effect of nixtamalization process on the content and composition of phenolic compounds and antioxidant activity of two sorghums varieties. J Cereal Sci 77: 1-8.

4. C Ciacci (2007) Celiac disease: In vitro and in vivo safety and palatability of wheat-free sorghum food products. Clin Nutr 26(6): 799-805.

5. P Koehler, H Wieser (2012) Chemistry of Cereal Grains. Handbook on Sourdough Biotechnology, USA. p. 11-45.

6. P Pontieri (2013) Sorghum, a Healthy and Gluten-free Food for Celiac Patients as Demonstrated by Genome, Biochemical, and Immunochemical Analyses. J Agric Food Chem 61(10): 2565-2571.

7. S. Althwab, TP Carr, CL Weller, IM Dweikat, V Schlegel, et al. (2015) Advances in grain sorghum and its co-products as a human health promoting dietary system. Food Res Int 77: 349-359.

8. TP Carr, CL Weller, VL Schlegel, SL Cuppett, DM Guderian, et al. (2005) Non-HDL Cholesterol Concentration in Hamsters 1, 2. Analysis pp. 22362240 .

9. JT Hoi, CL Weller, VL chlegel, SL Cuppett, JY Lee, et al. (2009) Sorghum distillers dried grain lipid extract increases cholesterol excretion and decreases plasma and liver cholesterol concentration in hamsters. J Funct Foods 1(4): 381-386.

10. I Martínez (2009) Diet-induced metabolic improvements in a hamster model of hypercholesterolemia are strongly linked to alterations of the gut microbiota. Appl Environ Microbiol 75(12): 4175-4184.
11. L Dykes, LM Seitz, WL Rooney, LW Rooney (2009) Flavonoid composition of red sorghum genotypes. Food Chem 116 (1): 313-317.

12. R Liu, C Xu, X Cong, T Wu, Y Song, et al. (2017) Effects of oligomeric procyanidins on the retrogradation properties of maize starch with different amylose/amylopectin ratios. Food Chem 221: 2010-2017.

13. AL Burdette (2007) Nutraceutical Uses of Sorghum Bran (Sorghum Bicolor). 1: 159.

14. CH Shih (2007) Quantitative Analysis of Anticancer 3-Deoxyanthocyanidins in Infected Sorghum Seedlings. J Agric Food Chem 55(2): 254-259.

15. Yang L, Browning JD, Awika JM (2009) Sorghum 3-deoxyanthocyanins possess strong phase II enzyme inducer activity and cancer cell growth inhibition properties. J Agric Food Chem 57(5): 1797-1804.

16. A Burdette, PL Garner, EP Mayer, JL Hargrove, DK Hartle, et al. (2010) Anti-Inflammatory Activity of Select Sorghum (Sorghum bicolor) Brans. J Med Food 13(4): 879-887.

17. KF Benson, JL Beaman, B Ou, A Okubena, O Okubena, et al. (2013) West African Sorghum bicolor leaf sheaths have anti-inflammatory and immune-modulating properties in vitro. J Med Food 16(3): 230-238.

18. TJ Shim, TM Kim, KC Jang, JY Ko, DJ Kim, et al. (2013) Toxicological Evaluation and Anti-Inflammatory Activity of a Golden Gelatinous Sorghum Bran Extract. Biosci Biotechnol Biochem 77(4): 697-705.

19. NJ Salazar Lopez (2016) The Extrusion Process as an Alternative for Improving the Biological Potential of Sorghum Bran: Phenolic Compounds and Antiradical and Anti-Inflammatory Capacity. Evidencebased Complement Altern Med p. 1-8.

20. C Gómez Cordovés, B Bartolomé, W Vieira, VM Virador (2001) Effects of wine phenolics and sorghum tannins on tyrosinase activity and growth of melanoma cells, J Agric Food Chem 49(3): 1620-1624.

21. JL Hargrove, P Greenspan, DK Hartle, C Dowd (2011) Inhibition of Aromatase and $\alpha$-Amylase by Flavonoids and Proanthocyanidins from Sorghum bicolor Bran Extracts. J Med Food 14(7-8): 799-807.

22. J Kim, Y Park (2012) Anti-diabetic effect of sorghum extract on hepatic gluconeogenesis of streptozotocin-induced diabetic rats. Nutr Metab (Lond) 9(1): 106.

23. JH Park, SH Lee, IM Chung, Y Park (2012) Sorghum extract exerts an antidiabetic effect by improving insulin sensitivity via PPAR- $\gamma$ in mice fed a high-fat diet. Nutr Res Proact 6(4): 322-327.

24. NDC Teixeira (2016) Resistant starch content among several sorghum (Sorghum bicolor) genotypes and the effect of heat treatment on resistant starch retention in two genotypes. Food Chem 197(ptA): 291296.

25. D Lemlioglu Austin, ND Turner, CM McDonough, LW Rooney (2012) Effects of sorghum [Sorghum bicolor (L.) moench] crude extracts on starch digestibility, estimated glycemic index (EGI), and resistant starch (RS) contents of porridges. Molecules 17(9): 11124-11138.

26. I Khan, A Yousif, SK Johnson, S Gamlath (2013) Effect of sorghum flour addition on resistant starch content, phenolic profile and antioxidant capacity of durum wheat pasta. Food Res Int 54(1): 578-586.

27. RL Shen, WL Zhang, JL Dong, GX Ren M Chen (2015) Sorghum resistant starch reduces adiposity in high-fat diet-induced overweight and obese rats via mechanisms involving adipokines and intestinal flora. Food Agric Immunol 26(1): 120-130.

28. S Wathsala, P Kyuho, H Hiroshi (2019) Influence of enzyme-resistant fraction of sorghum (Sorghum bicolor L.) flour on gut microflora composition, short chain fatty acid production and toxic substance metabolism. J Food Nutr 58(2): 135-145. 